\title{
SEGMENTAL DILATATION OF SMALL BOWEL
}

\section{A. Narendra Kumar ${ }^{1}$, Lavanya Kannaiyan², Venkateshwar Perugu ${ }^{3}$}

\section{HOW TO CITE THIS ARTICLE:}

A. Narendra Kumar, Lavanya Kannaiyan, Venkateshwar Perugu. "Segmental Dilatation of Small Bowel". Journal of Evolution of Medical and Dental Sciences 2015; Vol. 4, Issue 58, July 20; Page: 10242-10245,

DOI: $10.14260 /$ jemds/2015/1474

ABSTRACT: We present a rare case of antenatally diagnosed intestinal obstruction and its postnatal management.

KEYWORDS: Segmental Dilatation of bowel, Megaileum.

INTRODUCTION: Segmental Dilatation of small bowel is a rare but well documented entity. It is usually antenatally detected as small bowel mass or obstruction. The postnatal symptoms may not correlate with the antenatal diagnosis.

CASE REPORT: New born female child presented with an abdominal distention and constipation at 36 hours of life. On presentation the child had a mass palpable per abdomen. X-ray abdomen was done which showed a large cystic structure with air fluid levels in the right side of the abdomen pushing the bowel loops to the left (Figure 1). An ultrasound abdomen done was suggestive of mesenteric cyst. The children underwent a laparotomy on Day 3 of life. Inter operatively, there was a segmental dilatation of the ileum $10 \mathrm{~cm}$ in diameter, $20 \mathrm{~cm}$ from the ileocaecal junction. There was no luminal obstruction. There were no abnormal vessels. The dilated segment was uniformly. The rest of the small bowel and colon were normal in caliber (Figure 2). The dilated segment was excised and intestinal anastomosis was done. The child was allowed oral intake by day 5 and was discharged on the $8^{\text {th }}$ postoperative day. The histopathological examination showed increased goblet cells, attenuation of smooth muscle and absent ganglion cells in the dilated segment (Figure 3). The proximal and distal non-dilated segments showed the presence of normal ganglion cells and nerve plexus.

DISCUSSION: Segemental dilatation of intestine (SDI) is also known as mega ileum, ileal dysgenesis or giant meckels' diverticulum. It is usually associated with omphalocoele.(1) The bowel is three to four times the normal diameter.(2) Swenson and Rothauser proposed the following criteria to diagnose segmental dilation of small bowel:

1. limited bowel dilatation with a 3-to4-fold increase in size,

2. Abrupt transition between the dilated segment and normal bowel,

3. No intrinsic or extrinsic barrier distal to the dilatation,

4. A clinical picture of intestinal occlusion or subocclusion,

5. Normal neuronal plexus and 6. Complete recovery after resection of the affected segment.(2)

\section{The Etiology is Theorized to Arise from:}

1. Extrinsic intrauterine obstruction, (3)

2. Vitellointestinal bands, $(4)$

3. Local neuropathy or myopathy,(5) and

4. Probable vascular accidents resulting in myopathy, ${ }^{(6)}$ It is important to rule out the presence of Hirschsprung's disease, duplication of bowel or Meckel's diverticulum. 
SDI is usually discovered in the neonatal period.(1,7) The child may present with an antenatal diagnosis of mass abdomen (as in our patient) or postnatal mass abdomen or neonatal obstruction. In older children they may have persistent anemia, protein loosing enteropathy (From ulcerations due the heterotopic mucosa) ${ }^{(8)}$ or with associated Hirschsprung's disease.(1,7) In our patient, the proximal bowel and distal bowel were normal in caliber, the colon appears to be normal in size and thickness, hence ruling the presence of total colonic aganglionosis. The diagnosis is usually made intraoperatively. An X-ray abdomen can show a persistent dilated loop. An ultrasound or CT of the abdomen may show the dilated loop.(8)

Some studies have reported the presence of heterotrophic mucosa like gastric or pancreatic akin to duplication of bowel or Meckel's diverticulum. $(1,6,7)$ In our patient the dilatation was saccular, with a single cavity with proximal bowel entering and distal bowel exiting. The histopathology showed no evidence of heterotrophic mucosa, thereby ruling out the diagnosis of duplication of bowel.

Saha et al(6) proposed that there may intrinsic myopathy that leads to the segmental dilatation of the bowel. On histopathological examination of the dilated segments attenuation the smooth muscle along with absent ganglions cells were seen.

The treatment is straight forward with resection and anastomosis of the bowel segment. The post-operative recovery was uneventful. At follow up for three months, the child is thriving well.

\section{REFERENCES:}

1. Sam CJ. Segmental ileal dilatation in a child. Trop Gastroenterol. 2011 Jul-Sep; 32(3): 221-3.

2. Swenson O, Rothauser F. Segmental dilatation of the colon: a new entity. Am J Surg 1959; 97: 734-8.

3. Ratcliffe J, Tait J, Lisle D, Leditschke JF, Bell J. Segmental dilatation of the small bowel: report of three cases and literature review. Radiology. 1989; 171: 827-30.

4. Waters K J, Levine D, Lee E Y, Buonomo C, Buchmiller T L. Segmental dilatation of the ileum: diagnostic clarification by prenatal and postnatal imaging. J Ultrasound Med. 2007; 26: 1251-6.

5. Cheng W, Lui VCH, Chen QM, et al. Enteric nervous system, interstitial cells of Cajal, and smooth muscle vacuolization in segmental dilatation of jejunum. J Pediatr Surg 2001; 36: 930-5.

6. Saha S, Konar H, Chatterjee P, Basu KS, Chatterjee N, Thakur S B, Dasgupta A. Segmental ileal obstruction in neonates--a rare entity. J Pediatr Surg. 2009 Sep; 44(9): 1827-30.

doi: 10.1016/j.jpedsurg.2009.05.035.

7. Ben Brahim M, Belghith M, Mekki M, Jouini R, Sahnoun L, Maazoun K, Krichene I, Golli M, Monastiri K, Nouri A. Segmental dilatation of the intestine. J Pediatr Surg. 2006 Jun; 41(6): 1130-3.

8. Oberhelman AP, Herman TE, McAlister WH, Keating JP, Rollins MD, Dillon PA. CT manifestations of ileal dysgenesis. Paediatr Radiol. 2007; 37: 209-12. 


\section{CASE REPORT}

Figure 1: X-ray abdomen showing a large cystic structure with air fluid levels in the right side of the abdomen pushing the bowel loops to the left.

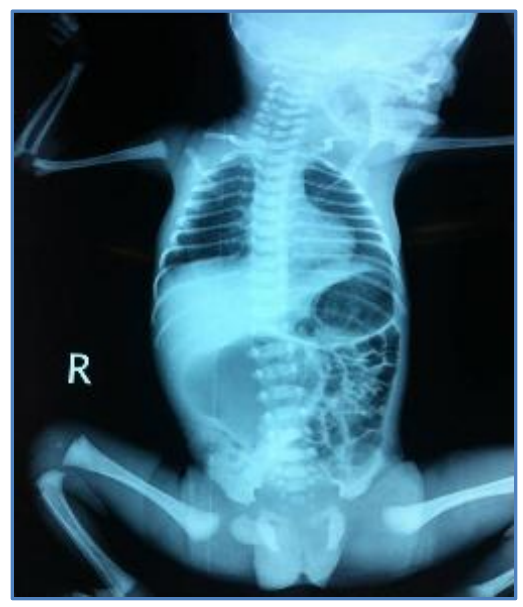

Fig. 1

Figure 2: Intraoperative picture showing the dilated segment of ileum and normal caliber proximal and distal ileum.

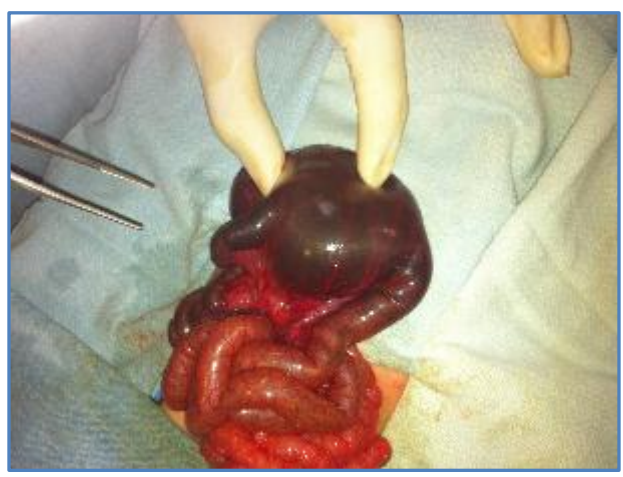

Fig. 2

Figure 3: Histopathological picture showing increased goblet cells, attenuation of smooth muscle and absent ganglion cells in the dilated segment.

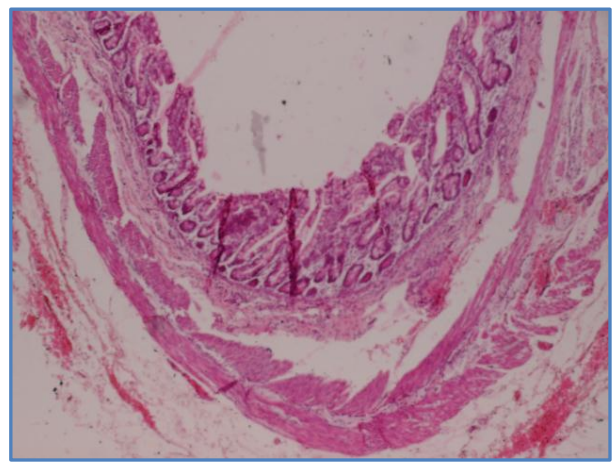

Fig. 3 


\section{CASE REPORT}

\section{AUTHORS:}

1. A. Narendra Kumar

2. Lavanya Kannaiyan

3. Venkateshwar Perugu

\section{PARTICULARS OF CONTRIBUTORS:}

1. Chief Pediatric Surgeon, Department of Paediatric Surgery, Lotus Children's Hospitals, Hyderabad, Telangana, India.

2. Paediatric Surgeon, Department of Paediatric Surgery, Lotus Children's Hospitals, Hyderabad, Telangana, India.

FINANCIAL OR OTHER

COMPETING INTERESTS: None
3. Paediatric Surgeon, Department of Paediatric Surgery, Lotus Children's Hospitals, Hyderabad, Telangana, India.

\section{NAME ADDRESS EMAIL ID OF THE CORRESPONDING AUTHOR:}

Dr. A. Narendra Kumar, \#304, Lake Villa Apartments, 6-3-1186/87, Green Lands, Begumpet, Hyderabad-500016,

Telangana, India.

E-mail: naren.are.1961@gmail.com

Date of Submission: 24/06/2015.

Date of Peer Review: 25/06/2015.

Date of Acceptance: 13/07/2015.

Date of Publishing: 20/07/2015. 